\title{
Self-care practices among type 2 diabetes mellitus patients in rural India
}

\author{
Richitha Shivananda ${ }^{1}$, Madhav K. Savkar ${ }^{1}$, Ravi Shankar Manchukonda ${ }^{1 *}$, \\ Raghavendra Srirangapura Krishnegowda ${ }^{2}$
}

\author{
${ }^{1}$ Department of Pharmacology, Adichunchanagiri Institute of Medical Sciences, B G Nagara, Karnataka, India \\ ${ }^{2}$ Department of Community Medicine, Adichunchanagiri Institute of Medical Sciences, B G Nagara, Karnataka, India
}

Received: 01 September 2020

Accepted: 05 October 2020

*Correspondence:

Dr. Ravi Shankar Manchukonda,

Email: drravishankarm@bgsaims.edu.in

Copyright: $@$ the author(s), publisher and licensee Medip Academy. This is an open-access article distributed under the terms of the Creative Commons Attribution Non-Commercial License, which permits unrestricted non-commercial use, distribution, and reproduction in any medium, provided the original work is properly cited.

\begin{abstract}
Background: The prevalence of diabetes mellitus (DM) has been increasing all over the world in past 30 years, particularly in the Indian subcontinent with an estimated $87 \%$ diabetic population within the age group 20-70 years. The increase in severity of diabetes every year has been linked to patient's lack of knowledge and practice of self-care. Hence educating the population as well as assessing their self-care practices has become important.

Methods: A cross-sectional study with 253 participants was done using the diabetic self-management questionnaire (DSMQ). Socio demographic details were also collected along with the questionnaire. The questionnaire was scored reversing the negatively worded questions (with a minimum score of 10 to maximum score of 34) and the $p$ values and Pearson's correlation was used to determine the significance of factors like age and gender with self-care practices.

Results: Among 253 subjects, 117 (46.2\%) participants felt that their self-care practices were poor to a 'considerable extent', hence the self-care practices of type $2 \mathrm{DM}$ in rural population was poor and factors like age and gender didn't show any significance in overall self-care of type 2 DM.

Conclusions: The self-care practices of type $2 \mathrm{DM}$ patients in rural area is poor. Age and gender had no significance in the self-care practices of type $2 \mathrm{DM}$ patients. Hence awareness programs should be done in order to educate the rural population about the importance of self-care in dealing with the complications of diabetes.
\end{abstract}

Keywords: Self-care practices, Type 2 DM, Diabetic self-management questionnaire, DSMQ

\section{INTRODUCTION}

Diabetes mellitus (DM) comprises a group of metabolic disorders that share the common feature of hyperglycemia. Type $1 \mathrm{DM}$ is characterized by insulin deficiency and a tendency to develop ketosis, whereas type 2 DM is a heterogeneous group of disorders characterized by variable degrees of insulin resistance, impaired insulin secretion, and excessive hepatic glucose production. ${ }^{1}$

The prevalence of DM has been increasing all over the world in past 30 years, particularly in the Indian subcontinent. According to international diabetic federation about 425 million people have diabetes in the world and about 82 million in south East Asia which by 2045 will rise to 151 million. Diabetes is a growing challenge in India with estimated $87 \%$ Diabetic population in the age group 20-70, and ischemic heart disease, peripheral vascular disease, and cerebrovascular disease (macro vascular), resulting in organ and tissue damage in approximately one third to one half of people with diabetes. $^{2,3}$

Self-care in diabetes is defined as the behavior undertaken by people with or at risk of diabetes in order to successfully manage the disease on their own. ${ }^{4}$ Self-care management 
of diabetes is complex. It needs a multifaceted approach which requires the patient to follow certain guidelines such as healthy eating, being physically active, regular monitoring of blood sugars, taking regular medication, good problem-solving skills, healthy coping skills and risk-reduction behavior to achieve optimum glycemic control and prevent complications in future. ${ }^{5-9}$ The increase in severity of diabetes every year has been linked to patients lack of knowledge and practice of self-care. ${ }^{10}$

The needs of diabetic patients are not only limited to adequate glycemic control but also correspond with preventing complications, disability limitation and rehabilitation. Some of the Indian studies revealed very poor adherence to treatment regimens due to poor attitude towards the disease and poor health literacy among the general public. ${ }^{11}$

This participation can succeed only if those with diabetes and their health care providers are informed about taking effective care for the disease. It is expected that those with the greatest knowledge will have a better understanding of the disease and have a better impact on the progression of the disease and complications.

\section{METHODS}

\section{Study design}

This study undertaken is a cross-sectional questionnaire based study.

\section{Study setup}

The study was conducted at the Rural health training centre (RHTC) associated to the Adichunchanagiri Institute of Medical Sciences, B G Nagara.

\section{Study duration}

Study was conducted for the duration of 2 months.

\section{Study participants}

The participants of our study included patients with type 2 DM aged 20 years and above with at least one-month duration of illness prior to the study.

\section{Criteria for subject selection}

\section{Inclusion criteria}

Patients aged 20 years and above with at least one month duration of illness prior to study and those who gave consent were included in the study.

\section{Exclusion criteria}

Patients with physical disability and mental illness were excluded.

\section{Ethical committee clearance}

Ethical approval was obtained from the AIMS Institutional ethics committee (IEC).

\section{Methodology}

Sample estimation

Prevalence of type $2 \mathrm{DM}(\mathrm{p})=28.3 \%^{12}$

$q=(100-p) ; d=20 \%(p)$

By the formula:

$$
n=4 p r \div d^{2}
$$

the sample size of our study will be 253 .

\section{Method of data collection}

The information regarding self-care activities among patients with type 2 DM was collected using Diabetes selfmanagement questionnaire (DSMQ). ${ }^{13}$ The DSMQ was 1 st developed at the Research Institute of the Diabetes academy, Mergentheim. The questionnaire contains sixteen items which includes questions based on 'glucose management', 'dietary control', 'physical activity', 'health care use' and the one item based on an overall rating of self-care. The questionnaire was validated based on the responses of the patients from 0-3 with 0-'does not apply to me', 1-'applies to me to a considerable amount', 2'applies to me to a considerable degree', 3-'applies to me very much'. Scoring involved reversing of negatively worded items such that higher values will indicate more effective self-care. The minimum score for the questionnaire was 10 and the maximum was 34 .

Besides the self-care aspects we also collected information in relation to socio-demographic characteristics of the participants such as age, gender, marital status, occupation, alcohol consumption, socio-economic status, medications, co morbidity and complications etc. The socio-economic status will be calculated using modified BG Prasad scale (as it is used for rural areas). $P$ values and Pearson's correlations was used to determine the significance of diabetes with factors like age and gender.

\section{RESULTS}

The study population consists of males $145(57.3 \%)$ and females 108 (42.7). Majority of the subjects were married 252 (99.6) and were Hindus 246 (97.2). Most of them belonged to an age group >60 years $119(47 \%)$ and were agriculturists $148(58.5 \%)$ with the next major population being housewives $42(16.6 \%)$ and the remaining belonged to various other professions like carpentering, taxi driving, teaching etc. $186(73.5 \%)$ subjects were with less than or equal to 5 people in a family and $67(26.5 \%)$ with $>5$ people in a family. Majority of them were moderately built 175 
(69\%) among which $72(28.4 \%)$ were females and 103 $(40.7 \%)$ were males. There was a genetic predisposition for type $2 \mathrm{DM}$ in $159(37.2 \%)$ and there were $72(28.5 \%)$ participants with associated diabetic complication like diabetic foot, delayed wound healing, cardiac complications, diabetic nephropathy etc. 132 (52.2\%) subjects were associated with other co morbid diseases like hypertension, asthma, tuberculosis, and 41 (16.2\%) of the participants were alcoholics.

Among the 250 subjects 100 (40\%) belonged to the lower middle class and 73 (29.2\%) belonged to lower class. (Calculated using the modified B.G.Prasad classification for rural population represented in Table 1).

Table 1: Socioeconomic status of the subjects using the modified B.G.Prasad classification.

\begin{tabular}{|lll|}
\hline & $\begin{array}{l}\text { Per capita income } \\
\text { (in Rupees) }\end{array}$ & n \\
\hline Lower class & 1050 and below & 73 \\
\hline $\begin{array}{l}\text { Lower middle } \\
\text { class }\end{array}$ & $1051-2101$ & 100 \\
\hline Middle class & $2102-3503$ & 48 \\
\hline $\begin{array}{l}\text { Upper middle } \\
\text { class }\end{array}$ & $3504-7007$ & 20 \\
\hline Upper class & 7008 and above & 12 \\
\hline
\end{tabular}

On comparing the age and diabetic complications it was seen that diabetic complications were seen more in the age group >60 years 37 (14.6\%) (graph 1). Similarly, on comparing the gender with diabetic complications, males $51(20.1 \%)$ showed more complications when compared to females (graph 2).

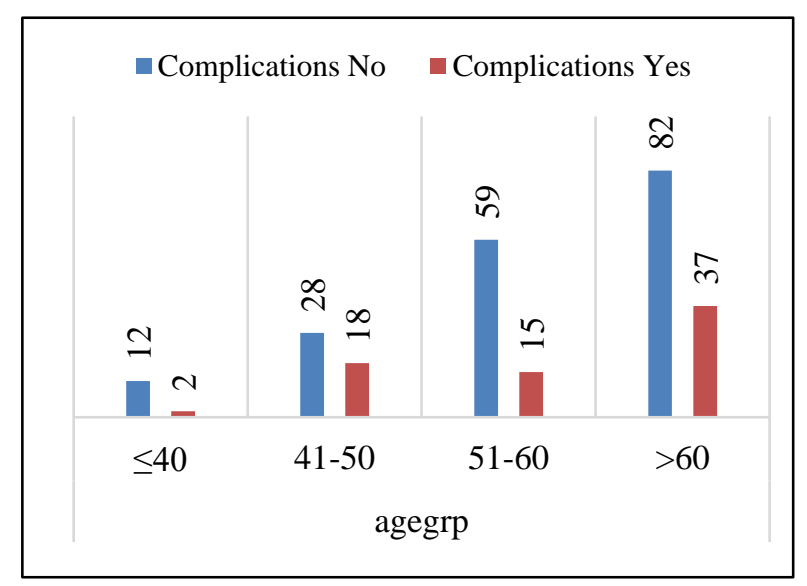

Figure 1: Age versus complications.

Comorbidities like hypertension, tuberculosis and asthma when compared with age of the subjects predominantly showed that subjects $>60$ years $74(29.2 \%)$ showed more incidence of co morbidity (graph3). Similarly, on comparing gender with comorbidity it showed that males $70(27.6 \%)$ and females $62(24.5 \%)$ were associated comorbid diseases (graph4).

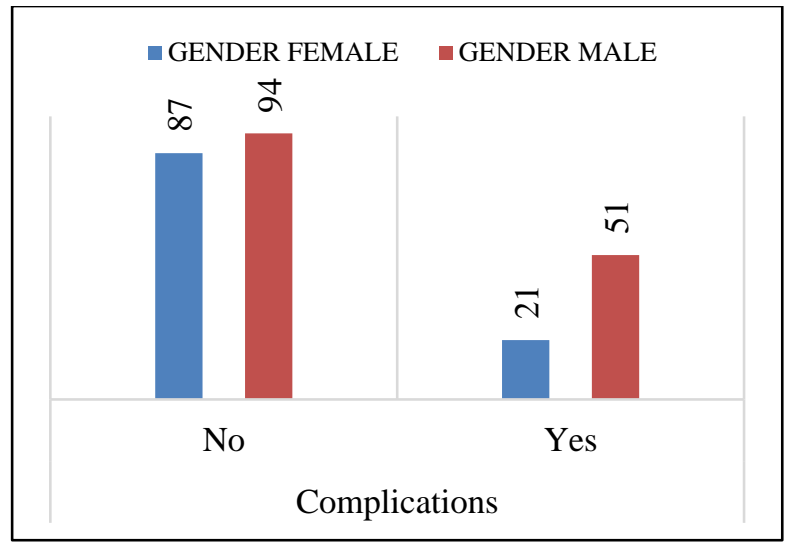

Figure 2: Gender versus complications.

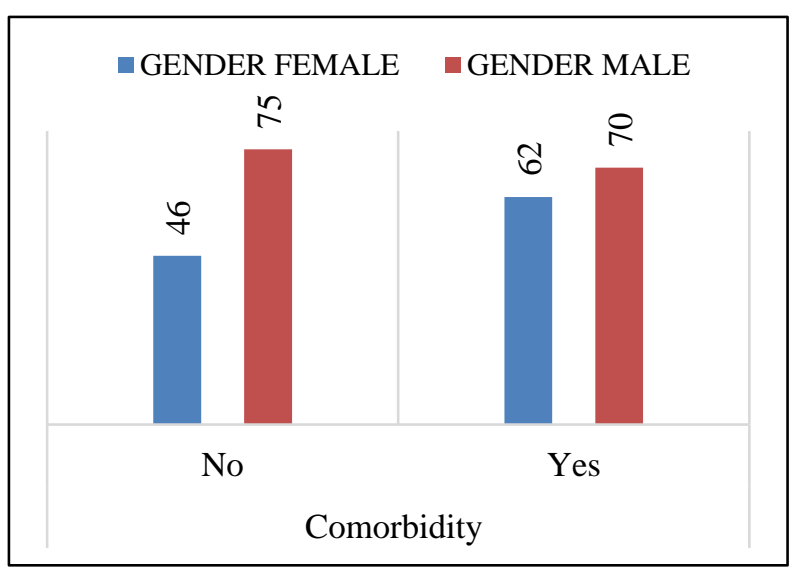

Figure 3: Gender versus comorbidity.

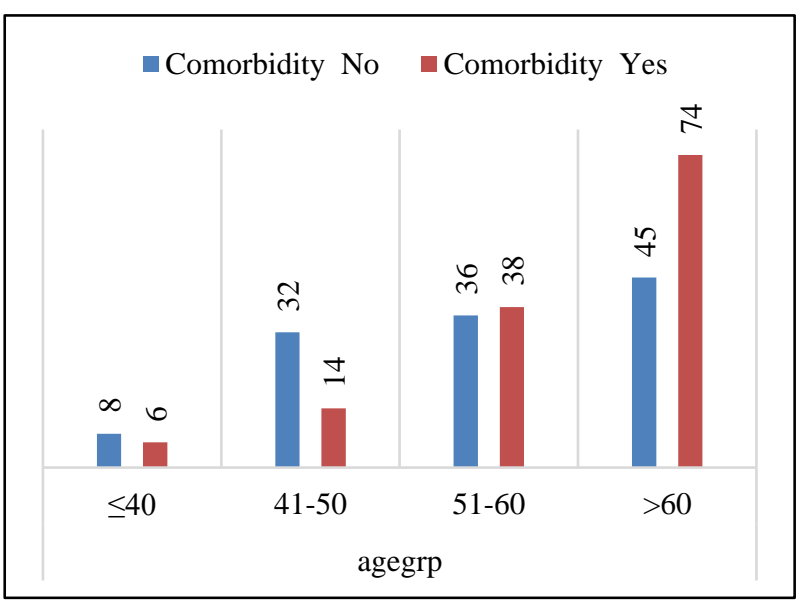

Figure 4: Age versus comorbidity.

\section{Analysis of the questionnaire}

Glucose management

$126(49.8 \%)$ of the subjects check their blood glucose with care and attention to 'considerable degree'. Only $16(6.3 \%)$ of the study population check their blood glucose 'strictly'. $168(66.4 \%)$ of subjects feel that they do not require the 
checking of blood sugar frequently in order to achieve good blood glucose control 'to some extent'.

\section{Dietary factors}

From the study $141(55.7 \%)$ participants feel that the food they choose to eat would help them achieve optimal blood sugar to a 'considerable degree'. Whereas only $5(2 \%)$ of the participants 'strongly believe' in the above. $116(45.8$ $\%$ ) subjects occasionally eat a lot of sweets and other carbohydrate rich food to 'to some extent' whereas 103 $(40.7 \%)$ of the study population eat them to a 'considerable extent'. Around $140(55.3 \%)$ of the study population strictly follow the dietary recommendations of the doctor for a 'considerable extent', whereas only $3(1.2 \%)$ of the population 'strictly follow' (very much) them. $133(52.6 \%)$ of the subjects have real food binges to a 'considerable extent' whereas 96 (37.9\%) have them to 'some degree'.

\section{Physical exercise}

$118(46.6 \%)$ of the participants do physical exercise to achieve optimum blood sugar level to a 'considerable extent' whereas around $101(39.9 \%)$ of the subjects diet only to 'some extent'. $145(57.3 \%)$ of the subjects avoid physical exercise even though it improved their diabetes to 'considerable extent'.

\section{Health care practices}

$139(54.9 \%)$ of the subjects keep all the doctor's appointments recommended for diabetic treatment to a 'considerable degree' whereas $89(35.2 \%)$ of the subjects keep them only to 'some extent'. 167 (66.0\%) subjects tend to avoid diabetes related appointments. 123 (48.6\%) believe that they should consult a medical practitioner for diabetic care to a 'considerable degree'.

\section{Medications}

$193(76.3 \%)$ of the subjects take their medication as prescribed for a 'considerable degree', whereas 31 (12.3\%) took their medication 'strictly' and $27(10.7 \%)$ of the subjects 'didn't take diabetic medications' at all.

Overall self-care: (opinion of the subjects regarding their own self-care) $130(51.4 \%)$ of the participants felt that their self-care practices are poor to 'some extent' whereas 117 $(46.2 \%)$ feel that the self-care practices are poor to a 'considerable extent' (Table 2).

From the study the minimum age of the subject was found to be 26 years and maximum age 91 years with a mean age of 60.02 years. The minimum per capita income was Rupees (Rs.) 110 and the maximum being Rs. 25000 with an average per capita income Rs. 2550.7. The minimum duration of diabetes ranged from less than a year (ranging from $>1$ month) to 34 years with an average of 7.93 years. From the total subjects who gave details about FBS (90) the minimum value was $82 \mathrm{gm} / \mathrm{dl}$ and the maximum value recorded was $432 \mathrm{gm} / \mathrm{dl}$ with an average FBS value of $178.9 \mathrm{gm} / \mathrm{dl}$. The PPBS values obtained from the subjects (98) ranged from 102-575 gm/dl with an average PPBS value being $259.68 \mathrm{gm} / \mathrm{dl}$ and the RBS values ranged from $100-693 \mathrm{gm} / \mathrm{dl}$ with an average of $238.9 \mathrm{gm} / \mathrm{dl}$. From the scoring of the questionnaire which included the reversal of negatively worded questions the minimum score was 10 and maximum was 34 (Table 3 ).

Table 2: Overall self-care based on the questionnaire.

\begin{tabular}{|lll|}
\hline Variables & Frequency & $\begin{array}{l}\text { Percentage } \\
(\%)\end{array}$ \\
\hline 0 (does not apply) & 2 & 0.8 \\
\hline $\begin{array}{l}\text { 1 (applies to some } \\
\text { extent) }\end{array}$ & 130 & 51.4 \\
\hline $\begin{array}{l}\text { 2 (applies to a } \\
\text { considerable } \\
\text { degree) }\end{array}$ & 117 & 46.2 \\
\hline $\begin{array}{l}\text { 3 (applies very } \\
\text { much) }\end{array}$ & 4 & 1.6 \\
\hline Total & 253 & 100.0 \\
\hline
\end{tabular}

Table 3: Questionnaire-based participant profile and laboratory blood glucose parameters.

\begin{tabular}{|llllll|}
\hline Age & N & Minimum & Maximum & Mean & SD \\
\hline Per capita income & 253 & 26 years & 91 years & 60.02 years & 11.541 \\
\hline Annual income of family & 253 & Rs 110 & Rs 25000 & Rs 2550.7 & 3544.9 \\
\hline Diabetic since & 253 & Rs 6000 & Rs 1200000 & Rs 123503.5 & 186492.3 \\
\hline Total score & 253 & $0(>1$ month) & 35 years & 7.93 years & 7.447 \\
\hline Glucose management & 253 & 10 & 34 & 23.00 & 3.457 \\
\hline Dietary control & 253 & 3 & 14 & 6.92 & 1.501 \\
\hline Physical activity & 253 & 3 & 10 & 6.13 & 1.415 \\
\hline Health care & 253 & 1 & 7 & 4.12 & .997 \\
\hline FBS & 253 & 0 & 9 & 4.34 & 1.082 \\
\hline PPBS & 90 & $82 \mathrm{gm} / \mathrm{dl}$ & $432 \mathrm{gm} / \mathrm{dl}$ & $178.91 \mathrm{gm} / \mathrm{dl}$ & 72.811 \\
\hline RBS & 98 & $102 \mathrm{gm} / \mathrm{dl}$ & $575 \mathrm{gm} / \mathrm{dl}$ & $259.68 \mathrm{gm} / \mathrm{dl}$ & 101.510 \\
\hline
\end{tabular}


Table 4: Association of self-care practices with gender.

\begin{tabular}{|c|c|c|c|c|c|}
\hline Gender & & n & Mean & Std. deviation & $P$ value \\
\hline \multirow{2}{*}{ Total } & Female & 108 & 23.09 & 3.441 & \multirow{2}{*}{0.728} \\
\hline & Male & 145 & 22.94 & 3.479 & \\
\hline \multirow{2}{*}{ Glucose management } & Female & 108 & 6.93 & 1.598 & \multirow{2}{*}{0.981} \\
\hline & Male & 145 & 6.93 & 1.432 & \\
\hline \multirow{2}{*}{ Dietary control } & Female & 108 & 6.21 & 1.381 & \multirow{2}{*}{0.492} \\
\hline & Male & 145 & 6.09 & 1.434 & \\
\hline \multirow{2}{*}{ Physical activity } & Female & 108 & 4.05 & 1.059 & \multirow{2}{*}{0.371} \\
\hline & Male & 145 & 4.16 & .947 & \\
\hline \multirow{2}{*}{ Health care } & Female & 108 & 4.38 & 1.078 & \multirow{2}{*}{0.695} \\
\hline & Male & 145 & 4.33 & 1.093 & \\
\hline
\end{tabular}

Table 5: Association of age and self-care.

\begin{tabular}{lllllll} 
& Total & $\begin{array}{l}\text { Glucose } \\
\text { management }\end{array}$ & $\begin{array}{l}\text { Dietary } \\
\text { control }\end{array}$ & Physical activity & Health care \\
\hline \multirow{2}{*}{ Age } & $\begin{array}{l}\text { Pearson } \\
\text { Correlation }\end{array}$ & -0.068 & $-0.132^{*}$ & 0.025 & 0.030 & -0.073 \\
\cline { 2 - 3 } & $\begin{array}{l}\mathrm{p} \text { value } \\
\mathrm{n}\end{array}$ & 0.280 & 0.036 & 0.689 & 0.638 & 0.249 \\
\hline
\end{tabular}

Table 4 shows the association of gender with self-care practices among type 2 diabetes patients. Here the total average scores of the questionnaire and average individual scores of each subcategory have been shown. The table implies that gender has no significance in overall self-care of type 2 diabetic patients.

The Pearson's correlation was used to determine the correlation of age in general (includes subjects with age $>20$ years) with that of self-care practices. The $\mathrm{p}$ values in the table depicts that the glucose management was associated with age whereas no other self-care parameters such as dietary factor, physical exercise and health care practices had any significance with that of age (Table 5).

\section{DISCUSSION}

Diabetes is a complex metabolic disorder characterized by high blood glucose levels over long period of time. The prevalence of DM is on the rise throughout the world. India is facing an epidemic with an estimated prevalence of 62 million. ${ }^{14}$ The high mortality and morbidity associated with diabetes mellitus is attributed to the vascular complications which occur frequently in patients with poor glycemic control.

Self-care in diabetes has been defined as an evolutionary process of development of knowledge or awareness by learning to survive with the complex nature of the diabetes in a social context. All the seven behaviors have been found to be positively correlated with good glycemic control, reduction of complications and improvement in quality of life. Self-monitoring provides information about current glycemic status, allowing for assessment of therapy and guiding adjustments in diet, exercise and medication in order to achieve optimal glycemic control. Irrespective of weight loss, engaging in regular physical activity has been found to be associated with improved health outcomes among diabetics. $^{12}$

Previously studies have been done to assess the self-care practices and their association with glycemic control and their relationship with diabetic complications but the present study aimed only towards assessing the self-care practices of type $2 \mathrm{DM}$ in rural population and factors affecting them.

Majority of the study population in the present study belonged to the age group $>60$ years $119(47 \%)$, but in the study by Peraje et al most of the subjects belonged to the age group 40-49 years (31\%), whereas in few other studies conducted in two places of Karnataka, namely Kolar and Dharwad, by Muninarayana et al and Patil et al respectively, the majority of the participants were in the age group of 30-45 and 30-49 years, respectively. ${ }^{15-17,29}$

The duration of illness in the study by Peraje et al 16 ranged from 1-5 years whereas in the present study it ranged from 0-35 years (as subjects with more than 1 month duration of the illness was included).

Dietary control: In the present study only $3(1.2 \%)$ of the study population 'strictly follow' (very much) the dietary recommendations whereas in the study by Peraje et al about 
$3 \%$ of the subjects followed the recommended diet (which included fruits and vegetables), but in a study conducted in rural Mysore by Srinath et al showed that $96.2 \%$ followed the recommended diet. ${ }^{15,18}$

Physical activity: In the present study 5 (2\%) of the study population 'strictly' follow/do regular physical activity whereas the $118(46.6 \%)$ of the population did regular physical activity to a 'considerable extent' whereas in a study by Peraje et al $19 \%$ of the participants strictly followed the recommended physical exercise .Similar finding was also seen in the study by Hailu et al. ${ }^{15,19}$

Glycemic control: In the present study 126 (49.8\%) of the subjects check their blood sugar levels with care for a 'considerable degree' whereas in a study by Peraje et al 5\% of the participants checked their blood sugars for least once in 3 months. ${ }^{15}$ Almost similar findings were seen in studies done elsewhere. ${ }^{20-22}$

Medications: Around $31(12.3 \%)$ of the participants 'strictly' take the medication prescribed by the physician whereas in a study by Peraje et al $48 \%$ of the participants take medication or hypoglycemic drugs but in a by Srinatha et al $92.5 \%$ showed compliance to diabetic medications. ${ }^{15,18}$

The present study also showed that there was no significance of gender with the overall self-care (which included glycemic control, dietary control, physical activity, health care practices). But age only showed significance in glycemic control and not in any other subscales of self-care. As a whole age also didn't have any significance in self-care.

\section{CONCLUSION}

The self-care practices of type $2 \mathrm{DM}$ patients in rural area is poor. Age and gender had no significance in the self-care practices of type $2 \mathrm{DM}$ patients. Hence awareness programs should be done in order to educate the rural population about the importance of self-care in dealing with the complications of diabetes.

\section{ACKNOWLEDGEMENTS}

We, the authors acknowledge the ICMR for creating and arousing interest towards scientific research in undergraduate students by undertaking ICMR-STS projects under which this proposal got selected and the research work was undertaken, completed and submitted, the same which was approved by ICMR.

Funding: No funding sources

Conflict of interest: None declared

Ethical approval: The study was approved by the Institutional Ethics Committee

\section{REFERENCES}

1. Kasper DL, Fauci AS, Hauser SL, Lango DL, Jameson JL, Loscalzo J, editors. In: Harrison's manual of medicine. 19th edition. New York: McGraw-Hill Education. 2016.

2. International Diabetic Federation. https://www.idf.org/our-network/regionsmembers/south-east-asia/members/94-india.html. Accessed on 22 January, 2019.

3. Cade WT. Diabetes-Related Microvascular and Macrovascular Diseases in the Physical Therapy Setting. Physical Thearphy. 2008;88(11):1322-35.

4. AADE. AADE7 self-care behaviors. Diabetes Educ. 2008;34(3):445-9.

5. American Diabetes Association. Evidence-based nutrition principles and recommendations for the treatment and prevention of diabetes and related complications. Diabetes Care. 2002;25(1):202-12.

6. Sigal RJ, Kenny GP, Wasserman DH, CastanedaSceppa C. Physical activity/exercise and Type 2 diabetes. Diabetes Care. 2004;27(10):2518-39.

7. Povey RC, Clark-Carter D. Diabetes and healthy eating: A systematic review of the literature. Diabetes Educ. 2007;33(6):931-59.

8. American Diabetes Association. Standards of Medical Care in Diabetes-2009. Diabetes Care. 2009;32(1):S13-61.

9. Deakin T, McShane CE, Cade JE, Williams RD. Group based training for self-management strategies in people with Type 2 diabetes mellitus. Cochrane Database Syst Rev. 2005;2:CD003417.

10. Ruchirawanitchathep W. Diabetic patients' knowledge, attitude and self-care in Roumachi primary care unit. Buddhachinaraj Medical Journal. 2008;25(1):60-6.

11. Shrivastava SR, Shrivastava PS, Ramasamy J. Role of self-care in management of diabetes mellitus. Journal of Diabetes and Metabolic Disorders. 2013;12:14.

12. Padmanabha UR, Nalam U, Badiger S, Nagarajaiah P. Prevalance and Risk Factors of Type 2 Diabetes Mellitus in the Rural Population of Mangalore, South India. National Journal of Community Medicine. 2017;8(8):456-61.

13. Lee NP, Fisher WP. Evaluation of the Diabetes SelfCare Scale. J Appl. 2005;6:366-81.

14. Kaveeshwar SA, Cornwall J. The current state of diabetes in India. AMJ. 2014;7:45-8.

15. Dinesh PV, Kulkarni AG, Gangadhar NK. Knowledge and Self-Care Practices Regarding Diabetes Among Patients with Type 2 Diabetes in Rural Sulia, Karnataka: A Community Based Cross Sectional Study. J Family Med Primlau. 2016:5(4):847-52.

16. Muninarayana $C$, Balachandra $G$, Hiremath SG, Iyengar K, Anil NS. Prevalence and awareness regarding diabetes mellitus in rural Tamaka, Kolar. Int J Diabetes Dev Ctries. 2010;30:18-21.

17. Patil PS, Dixit UR, Hiralal BD. Study of diabetes in Dharwad - An urban area in India. Indian $\mathrm{J}$ Sci Technol. 2011;4:1481-3. 
18. Srinath KM, Basavegowda M, Tharuni NS. Diabetic self-care practices in rural Mysuru, Southern Karnataka, India-A need for Diabetes SelfManagement Educational (DSME) program. Diabetes \& Metabolic Syndrome: Clinical Research \& Reviews. 2017;11:S181-6.

19. Hailu E, Wudineh HM, Belachew T, Birhanu Z. Selfcare practice and glycaemic control amongst adults with diabetes at the Jimma university specialized hospital in South-West Ethiopia: A cross-sectional study. Afr J Prim Health Care Fam Med. 2012;4:34-9.

20. Gopichandran V, Lyndon S, Angel MK, Manayalil BP, Blessy KR, Alex RG, et al. Diabetes self-care activities: A community-based survey in urban southern India. Natl Med J India. 2012;25:14-7.

21. Ayele K, Tesfa B, Abebe L, Tilahun T, Girma E. Selfcare behavior among patients with diabetes in Harari,
Eastern Ethiopia: The health belief model perspective. PLoS One. 2012;7:e35515.

22. Guo XH, Yuan L, Lou QQ, Shen L, Sun ZL, Zhao F, et al. A nationwide survey of diabetes education, selfmanagement and glycemic control in patients with type 2 diabetes in China. Chin Med J (Engl). 2012;125:4175-80.

Cite this article as: Shivananda R, Savkar MK, Manchukonda RS, Krishnegowda RS. Self-care practices among type 2 diabetes mellitus patients in rural India. Int J Basic Clin Pharmacol 2020;9:168894. 